\title{
Frictional Conditions of AA5251 Aluminium Alloy Sheets Using Drawbead Simulator Tests and Numerical Methods
}

\author{
Tomasz Trzepieciński1 - Hirpa G. Lemu2,** \\ 1 Rzeszow University of Technology, Department of Materials Forming and Processing, Poland \\ 2 University of Stavanger, Department of Mechanical and Structural Engineering and Materials Science, Norway
}

\begin{abstract}
This article presents research results on the effect of sheet metal surface roughness, lubricant conditions and sample orientation on the value of friction coefficient in the drawbead region of sheet metal-forming processes. Aluminium alloys with different temper conditions were used as test materials. The experimental results have ascertained several relationships showing the effect of surface profile and lubrication on the value of the friction coefficient. Based on experimental measurements, it may be concluded that the sample orientation and the lubrication conditions are crucial variables influencing the value of the coefficient of friction. Furthermore, a numerical model of the drawbead has been created in Msc.MARC Mentat software, and several simulations have been performed to study the stress/strain state in stretched sample during drawbead simulator tests. Both isotropic and anisotropic material models were used in the simulations taking into account the sample orientation with respect to the rolling direction of the sheet.
\end{abstract}

Keywords: coefficient of friction, drawbead, FEM simulation, friction, sheet metal forming

\section{O INTRODUCTION}

Deep drawing is a key manufacturing process for sheet metal products. The quality of the products and the efficiency of the drawing process depend on several parameters. Friction regimes encountered during deep drawing in particular are known to be extremely complex [1] and [2]. This is as a result of the inherent factors, such as the contact pressure, sliding velocity, surface roughness at sheet metal and tool interface, material properties of the tool and the blank, and the properties of the lubrication. Moreover, resistance to friction depends on texture anisotropy [3] and physicochemical factors acting on the contact surface and the dynamics of loads [4]. Previous studies show that friction at the microscopic level is due to adhesion between contacting asperities, the ploughing effect between asperities [5] and the appearance of hydrodynamic friction stresses [6] and [7]. Few regions of the draw piece with different stress and strain states, local sliding velocity, contact pressure and friction conditions exist.

General application of numerical simulations of sheet metal forming for proper functioning requires knowledge of suitable mathematical descriptions of friction behaviour. The finite element method (FEM) as a numerical analysis approach is currently widely used in sheet metal modelling and analysis. A description of the drawbead cannot generally be taken into account in the finite element simulation of sheet metal forming processes [8] and [9]. The small radii of the bead and the sharp corners of the die shoulders impose a certain meshing of the sheet passing the drawbead. At the same time, the role of the experimental approach remains essential [10] for developing numerical methods for the calculation of the friction coefficient and validating the results.

Performance of the forming process is secured by controlling the blank holder force, a straining force created by friction between the blank and the tools, which partially controls the material flow. This force cannot fully control the material flow, because it does not make a full contact with the entire blank. Fig. 1 illustrates the drawbead form in deep drawing and how it generates a stable tensile force opposite to the sheet drawing direction by introducing a series of local bending, straightening and reverse bending deformations on the sheet.

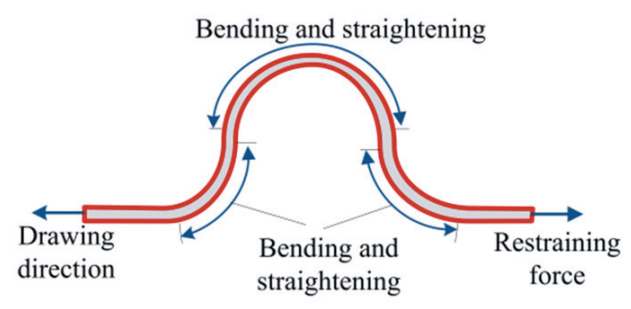

Fig. 1. Deformation of the sheet in drawbead region

This article presents the results of studies done on the two main problems: experimental research on frictional conditions of AA5251 aluminium alloys using a drawbead simulator friction test in accordance with the drawbead simulator (DBS) approach proposed by Nine [11], and numerical simulations based on the results of the friction test. 


\section{MATERIALS AND METHODS}

\subsection{Materials}

The first task conducted in this research was an experimental work in which four kinds of aluminium alloy sheets with different temper conditions were used. The sheets with temper $\mathrm{H} 14$ have a thickness of $0.8 \mathrm{~mm}$ while sheets with temper $\mathrm{O}, \mathrm{H} 16$ and $\mathrm{H} 22$ have a thickness of $1 \mathrm{~mm}$. The average sheet thickness varied between $\pm 0.01 \mathrm{~mm}$ as a result of the tolerance of the sheet metal fabrication process. A tensile test in the universal testing machine was carried out to determine the mechanical properties of the sheets. The mechanical properties determined in this test (as given in Table 1) are yield stress $R_{p 0.2}$, ultimate strength $R_{m}$, elongation $A_{50}$, anisotropy coefficient $r$, strain-hardening coefficient $C$ and strain-hardening exponent $n$. The samples for the tensile tests were cut in two directions: along the rolling direction $\left(0^{\circ}\right)$ and transverse to the rolling direction $\left(90^{\circ}\right)$. The mechanical properties of the sheets clearly show that the used aluminium alloy sheets have a wide range of $R_{p 0.2}$ values based on temper conditions.

\subsection{Surface Characterization}

The measurement of surface roughness parameters was carried out using the Alicona InfiniteFocus instrument. The main standard 3D parameters determined by this measurement (given in Table 2) are: the roughness average $S a$, the root mean square roughness parameter $S q$, the highest peak of the surface $S p$, the maximum pit depth $S v$, the surface skewness $S s k$, the surface kurtosis $S k u$, the 10-point peak-valley surface roughness $S z$, the density of summits $S d s$, the texture aspect ratio of the surface $S t r$, the surface bearing index $S b i$, the core fluid retention index $S c i$ and the valley fluid retention index Svi. The surface topography of tested materials is also

Table 1. The mechanical properties of the tested sheets

\begin{tabular}{lccccccc}
\hline \multirow{2}{*}{ Material } & \multirow{2}{*}{ Orientation $\left[^{\circ}\right]$} & \multicolumn{7}{c}{ Mechanical properties } \\
\cline { 2 - 8 } & & $R_{p 0.2}[\mathrm{MPa}]$ & $R_{m}[\mathrm{MPa}]$ & $A_{50}$ & $C[\mathrm{MPa}]$ & $n$ & $R$ \\
\hline \multirow{2}{*}{ AA5251 } & 0 & 68 & 203 & 0.18 & 252 & 0.279 & 0.607 \\
\cline { 2 - 8 } & 90 & 72 & 205 & 0.25 & 245 & 0.270 & 0.870 \\
\hline \multirow{3}{*}{ AA5251 H14 } & 0 & 212 & 234 & 0.04 & 254 & 0.058 & 0.478 \\
& 45 & 216 & 240 & 0.04 & 271 & 0.070 & 0.693 \\
\hline \multirow{2}{*}{ AA5251 H16 } & 90 & 210 & 241 & 0.04 & 327 & 0.078 & 0.786 \\
\hline \multirow{2}{*}{ AA5251 H22 } & 0 & 184 & 232 & 0.05 & 253 & 0.163 & 0.528 \\
\hline & 90 & 189 & 236 & 0.06 & 242 & 0.154 & 0.751 \\
\hline
\end{tabular}

Table 2. The surface roughness parameters of the tested sheets

\begin{tabular}{|c|c|c|c|c|c|c|c|c|c|c|c|c|}
\hline \multirow{2}{*}{ Material } & \multicolumn{12}{|c|}{ Surface roughness parameters } \\
\hline & Sa $[\mu \mathrm{m}]$ & $S q[\mu \mathrm{m}]$ & $S p[\mu \mathrm{m}]$ & $S v[\mu \mathrm{m}]$ & Ssk & Sku & $S z[\mu \mathrm{m}]$ & $S d s^{*}$ & Str & Sbi & Sci & Svi \\
\hline AA52510 & 0.302 & 0.376 & 2.37 & 1.39 & 0.267 & 3.48 & 3.26 & 749 & 0.029 & 0.241 & 1.64 & 0.110 \\
\hline AA5251H14 & 0.340 & 0.423 & 2.48 & 1.62 & 0.298 & 3.34 & 3.3 & 697 & 0.036 & 0.243 & 1.67 & 0.094 \\
\hline AA5251H16 & 0.362 & 0.41 & 2.98 & 2.08 & 0.338 & 3.67 & 3.51 & 685 & 0.041 & 0.255 & 1.58 & 0.112 \\
\hline AA5251H22 & 0.325 & 0.401 & 2.04 & 1.53 & 0.321 & 3.58 & 3.43 & 716 & 0.031 & 0.263 & 1.72 & 0.104 \\
\hline
\end{tabular}

* In [Peaks $\left./ \mathrm{mm}^{2}\right]$ or alternatively the unit [vertexes $\left./ \mathrm{mm}^{2}\right]$ can also be used.

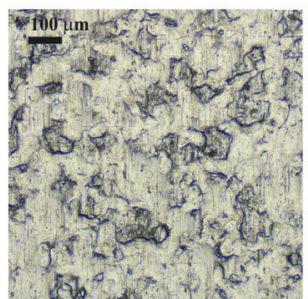

a)

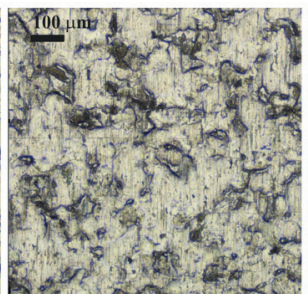

b)

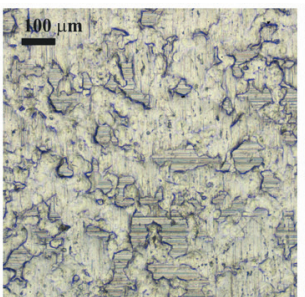

c)

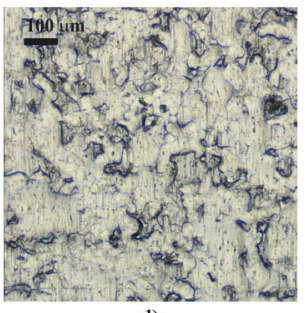

d)

Fig. 2. Surface topography of tested materials; a) AA5251 0, b) AA5251 H14, c) AA5251 H16, d) AA5251 H22 
shown in Fig. 2, where each tested surface has an area of $1.4301 \times 1.0849 \mathrm{~mm}$.

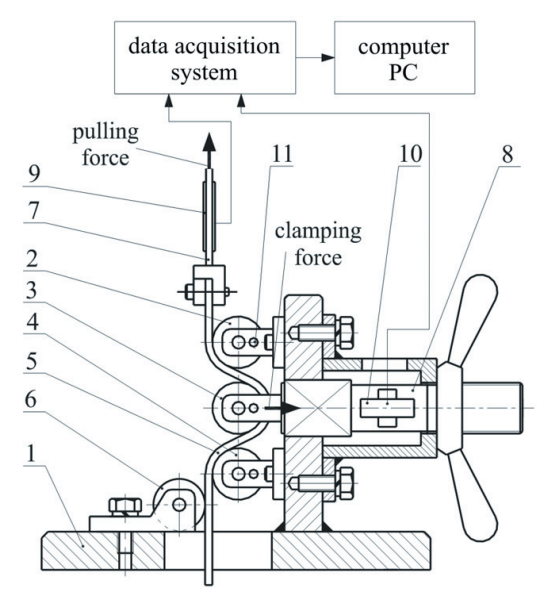

Fig. 3. Measurement system used for friction testing; 1 frame; 2 - front roll; 3 - middle roll; 4 - back roll; 5 - specimen; 6 - supporting roll; 7 and 8 - tension members; 9 and 10 extensometers; 11 - fixing pin

\subsection{Drawbead Test}

In the drawbead simulator test, the sheet metal was pulled to flow between three cylindrical rolls, each with a radius of $20 \mathrm{~mm}$ (Fig. 3). The rolls have been quenched and tempered according to a minimum of 57 HRC. The quenching temperature was $990^{\circ} \mathrm{C}$, and the temper temperature was approximately $500{ }^{\circ} \mathrm{C}$. The test material was cut along the rolling direction into $200 \mathrm{~mm}$ long and $20 \mathrm{~mm}$ wide strips. To realize various lubricated conditions, both rolls and sheet specimens were degreased by using acetone for dry friction conditions, and machine oil L-AN 46 of $44 \mathrm{~mm}^{2} \mathrm{~s}^{-1}$ viscosity at $40{ }^{\circ} \mathrm{C}$ was used for lubricated conditions. The lubricant was applied in excess to the test strips so that the film thickness could be determined by the process. The sliding speed was set to $1 \mathrm{~mm} / \mathrm{s}$ and various tribological conditions were obtained by using rolls with different surface roughness values $(R a=0.32,0.64$ and $1.25 \mu \mathrm{m})$ measured along the generating line of the rolls. The rolls were made of cold-worked tool steel X165CrV12.

The clearance between working rolls was adjusted and maintained at $1.5 t$ (where $t$ is the sheet thickness). The main purpose of this clearance is to prevent locking of the sheet between the rolls, especially for fixed rolls. The clearance value was estimated based on a trial-and-error method and experience. Taking the clearance into account, the total wrap angle around all rolls is about $310.48^{\circ}$, where the highest wrap angle is on the middle roll.
The pulling and clamping forces were controlled using load cells. To determine the coefficient of friction, carrying out two tests with two samples was found to be necessary. One specimen was pulled between cylindrical rolls supported by bearings, and then the measured pulling force (denoted as $D_{\text {roll }}$ ) and the clamping force $\left(C_{\text {roll }}\right)$ gave the bending and unbending resistance of the sheet under "frictionless" conditions, respectively.

The sheet is displaced between the rotating rolls so that the friction between the sheet and rolls is minimized while the second specimen is pulled between the fixed rolls. Friction opposes the sliding of the sheet over the fixed rolls. The combined loads required to slide and to bend/unbend the sheet with the fixed rolls are then given by the measured pulling force $\left(D_{f i x}\right)$ and the clamping force $\left(C_{f i x}\right)$.

When the wrap angle of middle rolls is $180^{\circ}$, the coefficient of friction is calculated according to the following expression [11]:

$$
\mu=\frac{D_{f i x}-D_{r o l l}}{\pi \cdot C_{f i x}}
$$

where $D_{f i x}$ is the pulling force obtained with the fixed rolls, $D_{\text {roll }}$ is the pulling force obtained with the freely rotating rolls, and $C_{f i x}$ is the normal force or clamping force obtained with the fixed beads.

It has been argued in a previous study [12] that the wrap angle corresponding to the actual engagement of the strip with the roller or bead was not taken into account in the derivation done by Nine [11]. Further, Green [13] states that the tangent-to-tangent bead wrap assumption becomes approximately valid only at extremely deep penetrations. This supports the argument that the validity of the equation derived by Nine [11] is limited to deep penetrations.

When the wrap angle is not equal to $180^{\circ}$ the friction coefficient is calculated from [14]:

$$
\mu=\frac{D_{f i x}-D_{\text {roll }}}{C_{f i x}} \cdot \frac{\sin \theta}{2 \theta}
$$

where $\theta$ is the quarter contact angle of actual engagement of the strip over the bead, and a value of $\theta=\pi / 2$ confirms a full penetration.

\section{NUMERICAL MODELLING}

The simulation of the drawbead simulator test was conducted using MSC.Marc + MENTAT 2010 
software. Both dry friction and oil-lubricated contacts were considered. The rolls were defined as rigid surfaces. While conducting the modelling, the aluminium sheet metal (AA5251 H14) was initially placed in a horizontal position and held by a frictionless device (Fig. 4a). At the initial stage, the middle roll was moved down to bend the sheet metal while the leading end of the sheet metal was fixed. The middle roll was allowed to travel through the distance at which the centres of curvature for both front and back rolls and the middle roll were at the same height (Fig. 4b). A displacement of $40 \mathrm{~mm}$ was then applied to one end of the sample when the required wrap angle was obtained. The numerical analyses were performed for the AA $5251 \mathrm{H} 14$ sheet tested in the following conditions: sample orientation $90^{\circ}, R a$ of rolls $0.63 \mu \mathrm{m}$, lubrication conditions.

The finite element model of the blank consists of 3600 quad4 shell elements with five integration points through the shell thickness, which are necessary for an acceptable solution [10]. The assumed strain formulation was applied to improve the bending characteristics of the elements. This can substantially improve the accuracy of the solution in terms of the computational costs of assembling the stiffness matrix. An elasto-plastic material model approach was implemented, and three material models have been simulated. In the first material model, the plastic behaviour of the metal was described by the von Mises yield criterion [15]. In the second model, the anisotropy of the material was established using the Hill yield criterion [16]. The Hill formulation is the most frequently used yield function in many research papers on steel sheet metal forming and can be regarded as an extension of the isotropic von Mises function. As reported by Cazacu and Barlat [17], the Hill formulation can also be applied for the material description of aluminium alloys.

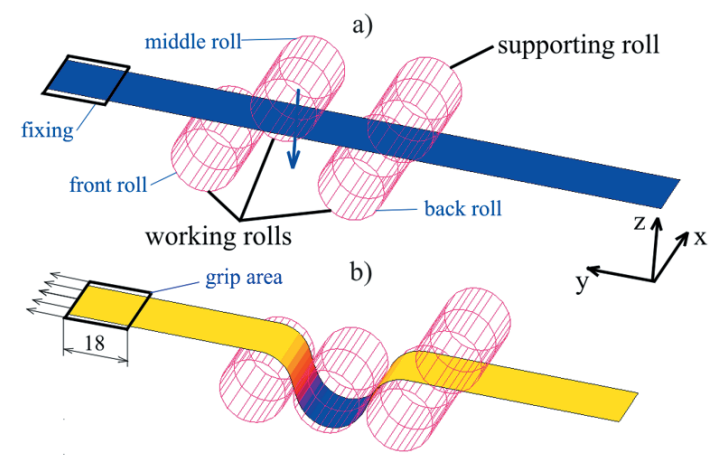

Fig. 4. Geometry and boundary conditions of FEM model of drawbead simulator test; a) initial configuration and b) start of drawing stage
The material behaviour for this second formulation is specified using the following properties: Young's modulus: $E=70000 \mathrm{MPa}$, Poisson's ratio $v=0.33$ and mass density $r=2690 \mathrm{~kg} \cdot \mathrm{m}^{-3}$. The isotropic hardening behaviour uses the Hollomon power-type law by which the parameters $C$ and $n$ (given in Table 1) are fitted on a stress-strain curve of the tensile test.

In the third model, the Barlat yield function has been applied [18]. In the case of anisotropy material models, both $0^{\circ}$ and $90^{\circ}$ sample orientations have been examined. The balanced biaxial yield stress $\sigma_{b}$ necessary to define Barlat material model was measured in a bulge test and a value of $278 \mathrm{MPa}$ was obtained. Simulations of friction tests were performed for rolls with surface roughness values of $R a=1.25 \mu \mathrm{m}$ in dry friction conditions. To describe contact conditions, the Coulomb friction law was applied (as described in an earlier publication by the same authors [19]).

\section{DISCUSSION OF EXPERIMENTAL RESULTS}

\subsection{Friction Coefficient Value}

In the friction tests, two sets of values for clamping and pulling forces determined for fixed and freely rotating rolls under dry friction and lubricated conditions were received. The average value of friction coefficient was determined from Eq. (1) after rejecting initial transient scope of load forces (Fig. 5).

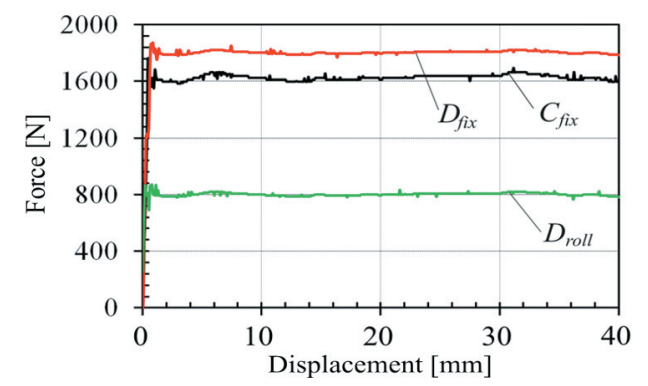

Fig. 5. Load characteristics of friction tests for AA5251 H14 under following conditions: Ra of rolls $1.25 \mathrm{~mm}$, dry friction, sample orientation at $0^{\circ}$

The average values of the coefficient of friction determined in dry friction $\mu_{d r y}$ and in lubricated conditions $\mu_{\text {oil }}$ are given in Table 3. Upon analysis of the friction test results, the expected relationships are observed. That means values of the friction coefficient in dry friction conditions are higher than those in lubrication conditions. The application of machine oil reduces the value of friction coefficient, but its 
intensity depends on the surface roughness of the rolls. This impact is not strongly evident and will be discussed in detail later in the article.

Table 3. Friction coefficient values of tested sheets

\begin{tabular}{|c|c|c|c|c|}
\hline \multirow{2}{*}{ Material } & \multirow{2}{*}{$\begin{array}{c}R a \text { (rolls) } \\
{[\mu \mathrm{m}]}\end{array}$} & \multirow{2}{*}{$\begin{array}{c}\text { Sample } \\
\text { orientation }\left[{ }^{\circ}\right]\end{array}$} & \multicolumn{2}{|c|}{ Coefficient of friction } \\
\hline & & & $\mu_{d r y}$ & $\mu_{\text {oil }}$ \\
\hline \multirow{6}{*}{ AA5251 0} & \multirow{2}{*}{0.32} & 0 & 0.259 & 0.205 \\
\hline & & 90 & 0.262 & 0.219 \\
\hline & \multirow{2}{*}{0.63} & 0 & 0.245 & 0.194 \\
\hline & & 90 & 0.251 & 0.201 \\
\hline & \multirow{2}{*}{1.25} & 0 & 0.219 & 0.161 \\
\hline & & 90 & 0.238 & 0.181 \\
\hline \multirow{6}{*}{ AA5251 H14 } & \multirow{2}{*}{0.32} & 0 & 0.245 & 0.190 \\
\hline & & 90 & 0.257 & 0.221 \\
\hline & \multirow{2}{*}{0.63} & 0 & 0.222 & 0.173 \\
\hline & & 90 & 0.243 & 0.196 \\
\hline & \multirow{2}{*}{1.25} & 0 & 0.193 & 0.140 \\
\hline & & 90 & 0.205 & 0.159 \\
\hline \multirow{6}{*}{ AA5251 H16 } & \multirow{2}{*}{0.32} & 0 & 0.242 & 0.183 \\
\hline & & 90 & 0.252 & 0.212 \\
\hline & \multirow{2}{*}{0.63} & 0 & 0.215 & 0.166 \\
\hline & & 90 & 0.225 & 0.169 \\
\hline & \multirow{2}{*}{1.25} & 0 & 0.188 & 0.135 \\
\hline & & 90 & 0.19 & 0.144 \\
\hline \multirow{6}{*}{ AA5251 H22 } & \multirow{2}{*}{0.32} & 0 & 0.238 & 0.175 \\
\hline & & 90 & 0.253 & 0.202 \\
\hline & \multirow{2}{*}{0.63} & 0 & 0.197 & 0.149 \\
\hline & & 90 & 0.207 & 0.157 \\
\hline & \multirow{2}{*}{1.25} & 0 & 0.185 & 0.134 \\
\hline & & 90 & 0.188 & 0.142 \\
\hline
\end{tabular}

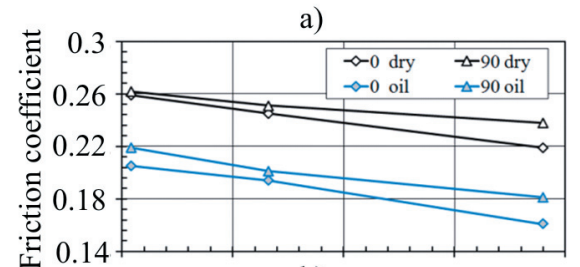

b)

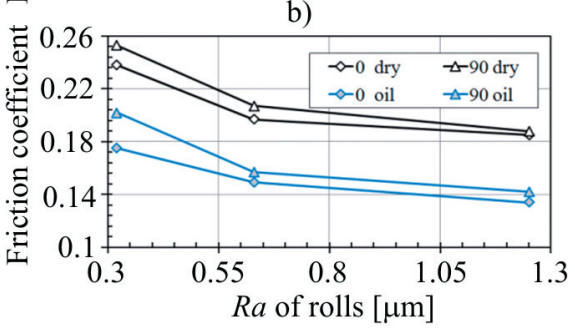

Fig. 6. Friction coefficient value vs. surface roughness [Ra] of rolls for a) AA5251 0, b) AA5251 H24

As the value of the $R a$ parameter of the rolls increases, the friction coefficient decreases for both dry friction and lubricated conditions (Fig. 6). The above-mentioned relations are valid for both sample orientations and for all tested materials. For all considered friction conditions, the friction coefficient values for samples cut across the rolling direction of the sheet are higher than for samples cut parallel to the rolling direction. The tested sheets exhibit directional surface topography caused by the manufacturing process of the sheets (rolling). The values of the 2D amplitude roughness parameters measured parallel to the rolling direction are lower than those measured in the transverse direction to the rolling direction. Furthermore, rolling causes directional orientation of the material grains parallel to the rolling direction, which is the source of anisotropy. In that case, the evolution of the surface topography during the sheet passing the draw bead is different for both sample orientations.

\subsection{Sheet Roughness}

The plot of the friction coefficient versus $S a$ parameter for the sheet AA5251 H22 is given in Fig. 7. It is observed in this plot that a local minimum of friction coefficient value at $S a=0.322 \mu \mathrm{m}$ exists.

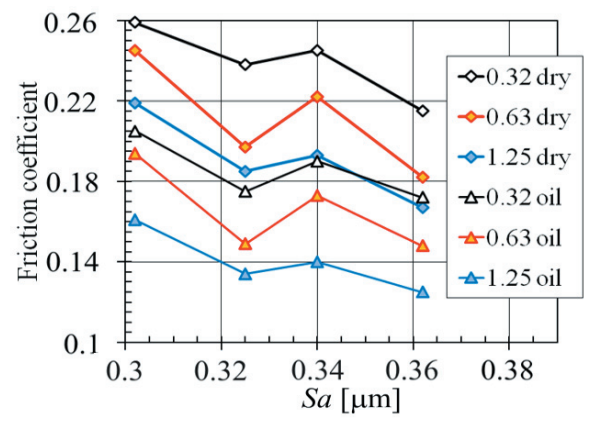

Fig. 7. The friction coefficient value vs. the roughness average Sa of the sheet for orientation at $0^{\circ}$

The above-mentioned relation is observed for all applied friction conditions, sample orientations and surface roughness of rolls, supports the conclusion that favourable conditions of friction reduction exist for this sheet.

Shih et al. [20] reported that roughening of asperities observed during stretching of the deformed material tends to decrease the real area of contact, resulting in a lower coefficient of friction. The continued increment of the value of friction coefficient for the sheet in this study (AA5251 H14) at $S a=0.34$ $\mu \mathrm{m}$ may be explained by the fact that (in spite of increasing surface roughness) the lubrication is unable to overcome the dominated metallic contact between the roughness asperities of contact bodies as the larger space contains the lubricant. 
Studies show that surface textures act either as micro-traps for capturing wear debris or as microreservoirs that enhance lubrication [21]. In the case of steel sheets [10] and [22], it is observed that higher $R a$ parameter value tends to produce lower friction, or this tendency is observed up to a certain $R a$ value and the value of friction coefficient increases. The roughness acts to separate the surfaces, isolating the areas of direct metallic contact. The larger the amplitude of the roughness, the less the area of contact grows for a given amount of sliding deformation. By limiting the area of direct contact during sliding, the adhesion and deformation components of friction are reduced and the valleys act to trap wear debris, reducing the amount of body wearing [22]. However, $\mathrm{Al}$ and $\mathrm{Al}$ alloys are relatively soft, and a mechanically mixed layer of ultrafine particles is formed due to deformation [23]. Thus, high $R a$ values can hardly produce wear debris that act as abrasive particles.

For all rollers used in the test, the relation between the $S a$ parameter and the friction coefficient value is similar. The friction coefficient value has the tendency to decrease with increases of the value of $S a$ parameters that represent different materials. Taking all of the obtained results into account, the relation between the value of $S a$ parameter and friction coefficient (Fig. 7) is found to be opposite to that reported in previous researches [10].

\subsection{Effect of Lubrication}

In order to reduce friction and minimize sheet failure, lubricants are typically applied to portions of the workpiece that undergo severe contact with dies. When lubricant is applied, the frictional resistance of the sheet material decreases and its strain uniformity increases. This means that the application of any lubricant should result in a reduction of the value of the friction coefficient.

Comparison of the values of the friction coefficient determined in dry friction and lubricated conditions demonstrate nearly linear relations (Fig. 9). This is particularly evident in the case of the sample orientation at $0^{\circ}$ (Fig. 9a).

The inclination angle of the trend line for sample orientation $0^{\circ}$ and $90^{\circ}$ are $42.32^{\circ}$ and $45.99^{\circ}$ respectively. When the sample has a $0^{\circ}$ orientation, a higher value of the friction coefficient in dry conditions is obtained, implying the higher effectiveness of lubrication. The relation for the sample orientation at $90^{\circ}$ (Fig. 9b) is the reverse.

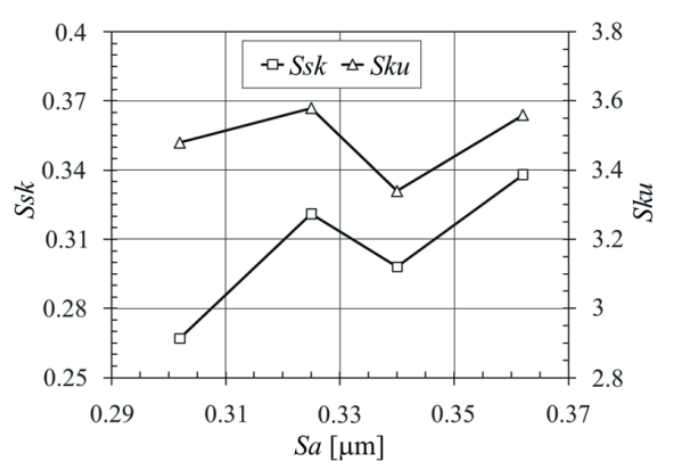

Fig. 8. Dependence of parameters Sa, Ssk and Sku of tested sheets

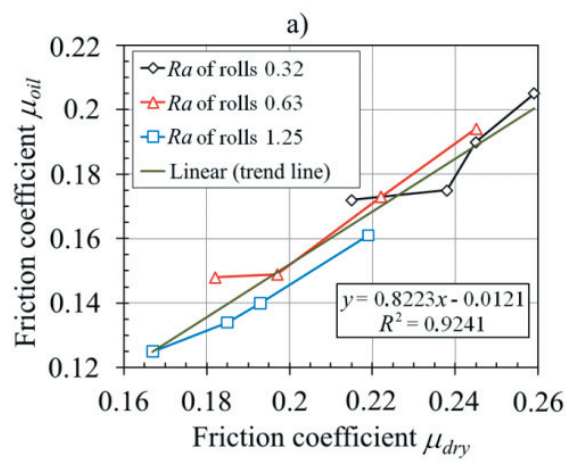

b)

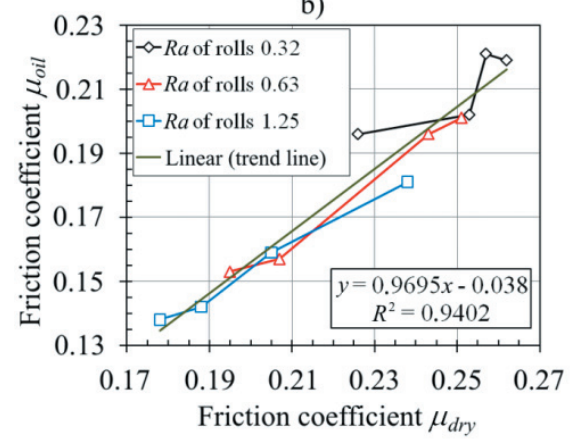

Fig. 9. Relation between the friction coefficients determined in dry friction conditions mdry and in lubrication conditions moil for orientation at (a) $0^{\circ}$ and (b) $90^{\circ}$

\subsection{Lubricant Effectiveness}

It is evident that rough surfaces enable lubricant adhesion to the sheet material. This effect appears to be due to the manner in which the lubricant is captured by rough areas on the surface of the sheet. To examine the effectiveness of the sheet lubrication, the L-index was introduced, defined as follows:

$$
L=\frac{\mu_{d r y}-\mu_{o i l}}{\mu_{d r y}} .
$$


As shown in Fig. 10, the $L$-index value has a nonlinear relation with the value of roughness parameter $R a$ of rolls. In the case of a sample orientation at $0^{\circ}$, the value of the $L$-index initially decreases and then shows an increasing tendency. For sample orientation at $90^{\circ}$, however, a continuous increasing trend of the $L$-index value is observed. The range of $L$-index value for the samples oriented at $0^{\circ}$ is higher $(0.19$ to 0.275$)$ than for the samples oriented at $90^{\circ}(0.132$ to 0.245$)$; therefore, in the case of the samples cut parallel to the rolling direction, lubricant highly reduced the friction coefficient value. There is no evident relation between the temper conditions of the sheet and $L$-index value, but for both orientations the sheet $\mathrm{H} 22$ exhibits the highest friction reduction. In all cases, the value of $L$-index is the highest for $R a=1.25 \mu \mathrm{m}$. As stated previously, in the case of higher surface roughness of contact bodies, a high volume of lubricant may be trapped in surface pits and, consequently, the effectiveness of lubrication is higher.
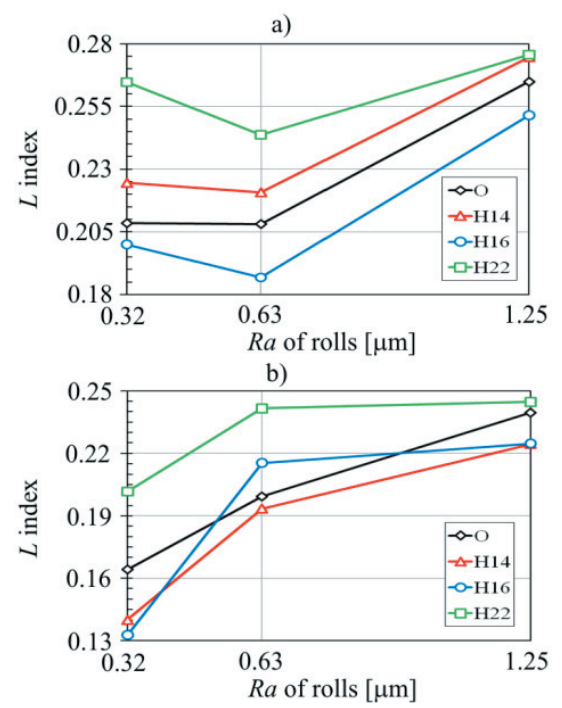

Fig. 10. Effectiveness of lubrication (L-index) as a function of $R$ a of rolls oriented at (a) 00 and (b) $90^{\circ}$

\section{DISCUSSION OF NUMERICAL RESULTS}

The numerical simulations include Hill's and Barlat's materials, and they were performed for both $0^{\circ}$ (designated as Hill $0^{\circ}$, Barlat $0^{\circ}$ ) and $90^{\circ}$ (designated as Hill $90^{\circ}$, Barlat $90^{\circ}$ ) sample orientations with respect to the rolling direction. The results show that the distributions of effective strain for different yield criteria during full penetration have been varying considerably (Fig. 11).

Maximal values of effective strains for Hill $0^{\circ}$ are higher than the values for sample cut transverse to the rolling direction by about 0.002 . A similar relationship exists for Barlat's material model. Furthermore, the points of occurrence of maximal effective strains depend on the considered material model.

The distributions of normal stress and shear stress in the transverse section after drawing a distance of $20 \mathrm{~mm}$ are shown in Fig. 12. The results in these plots show that the maximal values of the normal stress and shear stress for all material yield functions are at the edge of the sample. The values of Barlat's material model regarding both orientations are the closest to the isotropic model. The local minimum at the middle, i.e. section $0-\mathrm{A}^{\prime}$, is related with deformation of the sheets during bending over the rounded bead. It causes local contact of the sheet with the roll surface and thus the values of friction forces along the sample width are not constant. In the case of the Hill yield model at $0^{\circ}$ and $90^{\circ}$ orientation (Hill $0^{\circ}$ and Hill $90^{\circ}$, respectively), the distribution of normal stress on the width of the sample is more uniform.

The distribution of stresses for both analysed orientations is similar, but the sample orientation influences the value of stresses. The values of shear stress for Hill's yield functions are considerably lower than other models and are more uniform, especially in the middle part of the analysed width of the sample. The dominant factors in determining both restraint force and blank thinning of dual-phase steel are bead penetration, flow stress and strain hardening [24]. In contrast, the effects of anisotropy and strip drawing direction with respect to the rolling direction are found to be relatively less influential.

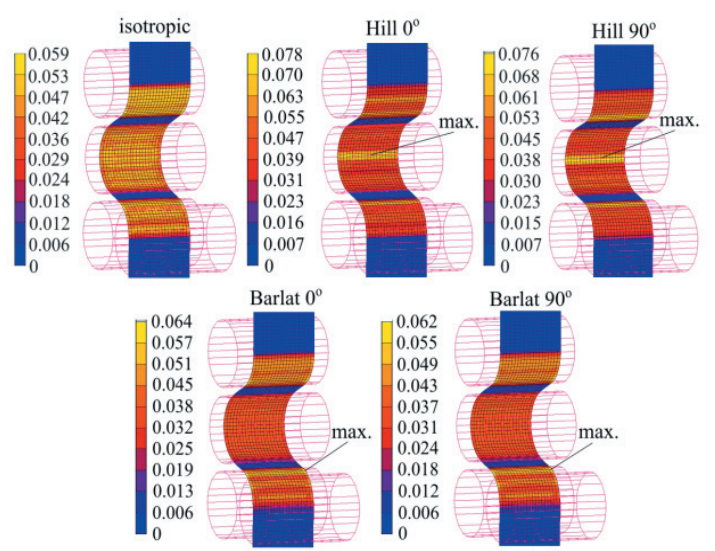

Fig. 11. The distribution of effective strain for different material models and sample orientations $0^{\circ}$ and $90^{\circ}$

The distributions of normal stress in longitudinal section after drawing a distance of $20 \mathrm{~mm}$ are shown in Fig. 13. The sequence of bending, unbending and reverse bending of the sheet material is clearly 
manifested by the cyclic normal stress observed on the longitudinal section of the drawbead region.

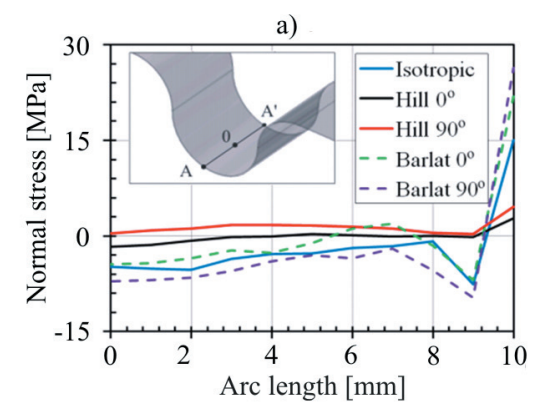

b)

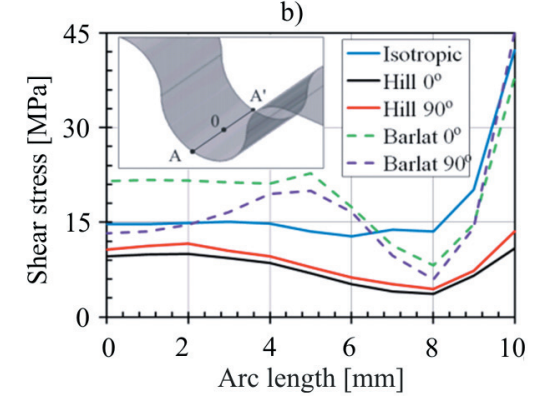

Fig 12. Stress distribution along $0-A^{\prime}$ section; a) normal stress and b) shear stress

The highest values of normal stress exist in the region of the middle roll - sheet contact (C-D) located on the side in accordance with the direction of sample pulling. The second peak of stress exists in the region of back roll, between $C^{\prime}-B^{\prime}$ points. The change of stress value from positive to negative is related with bending and unbending of the sheet. On the sample length within the drawbead, places exist where the normal stress equals zero.

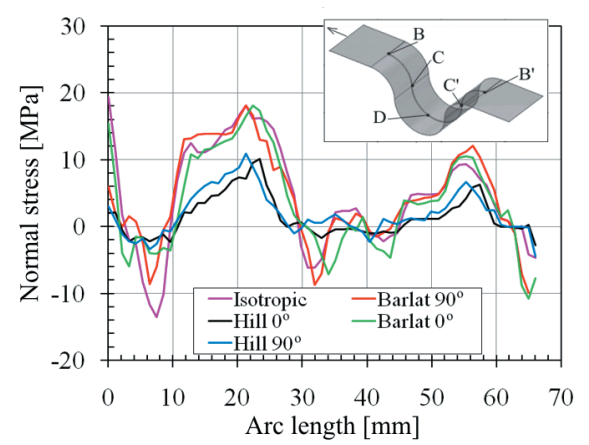

Fig. 13. Normal stress distribution along B-B' section

In addition to the comparative average values of friction test forces, the average value of the friction coefficient at the same stage and the error of numerically determined friction coefficient in relation to the experimental values are tabulated in Table 4 .
Table 4. Comparative experimental and numerical average values of friction test forces at the second stage of the friction simulator test

\begin{tabular}{lccccc}
\hline \multirow{2}{*}{ Source } & \multicolumn{3}{c}{ Force [N] } & Friction & Error [\%] \\
\cline { 2 - 5 } & $D_{\text {fix }}$ & $D_{\text {roll }}$ & $C_{\text {fix }}$ & coeff. & \\
\hline Experiment & 1803 & 801 & 1624 & 0.196 & - \\
\hline Isotropic model & 1712 & 775 & 1582 & 0.188 & -4.08 \\
\hline Barlat's model & 1817 & 822 & 1642 & 0.192 & -2.04 \\
\hline Hill's model & 1697 & 758 & 1574 & 0.189 & -3.57 \\
\hline
\end{tabular}

The results of the variation of numerically determined test force $D_{f i x}$ both at first and second stages (Fig. 14) show that all the numerical models over-predicted the value of the friction coefficient. The prediction errors of the friction coefficient for numerical models based on isotropic, Barlat's and Hill's material models are calculated to be 4.08, 2.04 and $3.57 \%$, respectively.

Furthermore, the value of average forces for the numerical model for Barlat's material model is the closest to the experimental one. For the rest of the FEM models (i.e., isotropic and Hill's material models), the average values of all test forces are proportionally smaller. As a result of this proportional decreasing tendency of the values of $D_{f i x}, D_{\text {roll }}$ and $C_{f i x}$, the value of friction coefficient does not diverge considerably from the experimental value (Fig. 15).

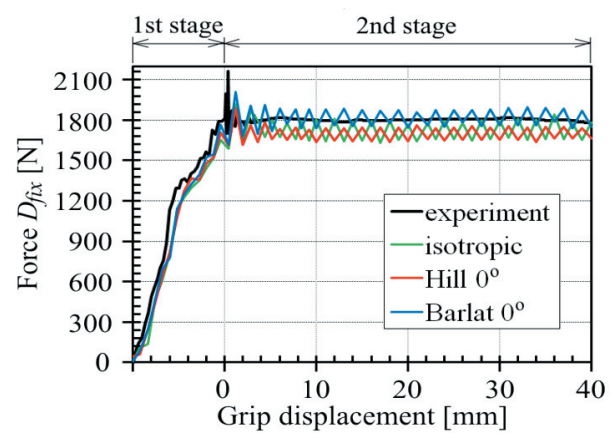

Fig. 14. The variation of numerical and experimental test force $D_{\text {fix }}$

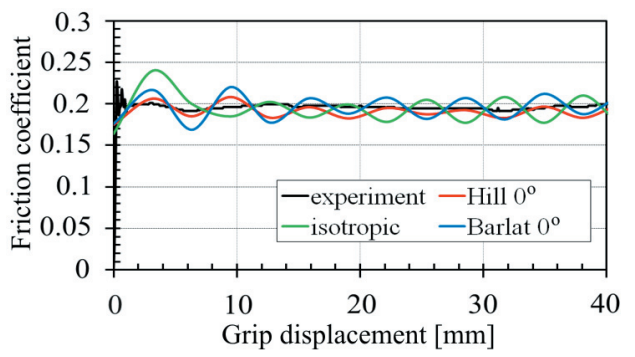

Fig. 15. The variation of friction coefficient value during frictional testing of the sample cut according to the rolling direction 


\section{CONCLUSIONS}

The material presented in this article is based on studies conducted using two main research approaches: experimental testing and numerical simulation. Numerical simulations are based on the aforementioned friction test using material model that is described by isotropic and anisotropic yield criteria.

The main results of the research can be summarized as follows:

1. Application of machine oil reduces the value of friction coefficient, but its intensity depends on the surface roughness of rolls.

2. For all applied friction conditions, the values of the friction coefficient for samples cut across the rolling direction of the sheet were higher than for samples cut in the rolling direction.

3. It has been found that the proposed $L$-index value has a non-linear relation with the value of the roughness parameter. For the sample orientation at $0^{\circ}$, the $L$-index value initially decreases and then continues to increase, while a continuous increase of the value is observed for the sample orientation at $90^{\circ}$.

4. The value of friction coefficient for both dry friction and lubrication conditions decreases as the surface roughness ( $R a$ parameter) of the rolls increases.

5. Sample orientation has a clear effect on the values of the friction coefficient and effectiveness of lubrication. When the sample is oriented at $0^{\circ}$, higher value of friction coefficient is obtained in dry conditions implying that the effectiveness of lubrication is higher. For a sample orientation at $90^{\circ}$, the relation is the reverse.

6. The yield criterion has a strong influence on the distribution of normal and shear stresses, but the results for the sample orientation at both $0^{\circ}$ and $90^{\circ}$ are quite similar.

7. The value of the normal stress on the width of the sheet varies. This requires sensitivity analysis of the effect of sample width on the sheet deformation in drawbead simulator friction test. In order to obtain representative results of numerical simulations of the Nine friction test, conducting a simulation of a $3 \mathrm{D}$ model of the drawbead is necessary.

8. In general, the results demonstrate that there is an agreeable harmony between the experimental and numerical models (FEM). The study on the friction coefficient shows prediction errors of less than $5 \%$, and among the selected yield criteria,
Barlat's material model has the best prediction with an error of about $2 \%$.

\section{ACKNOWLEDGEMENT}

This research was realized with financial support provided by Iceland, Liechtenstein and Norway and was co-financed by European Economic Area and Norwegian Financial Mechanism under the Scholarship and Training Fund. The authors would like to appreciate this financial support.

\section{REFERENCES}

[1] Yang, T.S. (2010). Investigation of the strain distribution with lubrication during the deep drawing process. Tribology International, vol. 43, no. 5, p. 1104-1112, DOI:10.1016/j.triboint.2009.12.050.

[2] Yang, T.S. (2007). A refined friction modeling for lubricated metal forming process. Tribology Letters, vol. 27, no. 3, p. 289-300, DOI:10.1007/s11249-0079233-x.

[3] Trzepieciński, T., Gelgele, H.L. (2011). Investigation of anisotropy problems in sheet metal forming using finite element method. International Journal of Material Forming, vol. 4, p. 357-359, DOI:10.1007/s12289-0100994-7.

[4] Liewald, M., Wagner, S., Becker, D. (2010). Influence of surface topography on the tribological behaviour of aluminium alloy 5182 with EDT surface. Tribology Letters, vol. 39, no. 2, p. 135-142. DOI:10.1007/ s11249-010-9625-1.

[5] Wilson, W.R.D. (1991). Friction models for metal forming in the boundary lubrication regime. Journal of Engineering Materials and Technology, vol. 113, no. 1, p. 60-68, DOI:10.1115/1.2903383.

[6] Lo, S., Yang, T. (2003). A new mechanism of asperity flattening in sliding contact - the role of tool elastic micro wedge. Journal of Tribology, vol. 125, no. 4, p. 713-719, DOI:10.1115/1.1574518.

[7] Yang, T.-S., Lo, S.W. (2006). Contact simulation for predicting surface topography in metal forming. Tribology Letters, vol. 23, no. 2, p. 121-129, DOI:10.1007/s11249-006-9112-x.

[8] Firat, M., Livatyali, H., Cicek, O., Fatih, O.M. (2009). Improving the accuracy of contact-type drawbead elements in panel stamping analysis. Materials and Design, vol. 30, no. 10, p. 4003-4011, DOI:10.1016/j. matdes.2009.05.022.

[9] Courvoisier, L., Martiny, M., Ferron, G. (2003). Analytical modelling of the drawbeads in the sheet metal forming. International Journal of Machine Tools \& Manufacture, vol. 133, no. 3, p. 359-370, DOI:10.1016/S0924-0136(02)01124-X.

[10] Trzepieciński, T. (2010). 3D elasto-plastic FEM analysis of the sheet drawing of anisotropic steel sheet metals. Archives of Civil and Mechanical Engineering. 
vol. 10, no. 4, p. 95-106, DOI:10.1016/s16449665(12)60035-1.

[11] Nine, H.D. (1978). Draw bead forces in sheet metal forming. Proceedings of Symposium on Mechanics of Sheet Metal Forming: Behavior and Deformation Analysis, Plenum Press, Warren, p. 179-211.

[12] Manjula, N.K.B., Nanayakkara, P., Hodgson, P.D. (2006). Determination of drawbead contacts with variable bead penetration. Computer Methods in Materials Science, vol. 6, no. 3, p. 188-194, DOI:10536/ DRO/DU:30004084.

[13] Green, D.E. (2001). An experimental technique to determine the behaviour of sheet metal in a drawbead. SAE Technical Paper Series, 2001-01-1136. DOI:10.4271/2001-01-1136.

[14] Nanayakkara, N.K.B.M.P., Kelly, G.L., Hodgson, P.D. (2004). Determination of the coefficient of friction in partially penetrated draw beads. Steel Grips, vol. 2, no. Supplement, p. 677-680, DOI:10536/DRO/ DU:30002855.

[15] von Mises, R. (1913). Mechanik der festen Körper im Plastisch deformablen Zustand, Nachrichten von der Köngl. Gesellschaft der Wissenschaften zu Göttingen, Mathematisch-Physikalische Klasse, Göttingen, p. 582592.

[16] Hill, R. (1948). A theory of the yielding and plastic flow of anisotropic metals. Proceedings of the Royal Society of London. Series A, Mathematical and Physical Sciences, vol. 193, no. 1033, p. 281-297, DOI:10.1098/ rspa.1948.0045.

[17] Cazacu, O., Barlat, F. (2003). Application of the theory of representation to describe yielding of anisotropic aluminium alloys. International Journal of Engineering
Science, vol. 41, no. 12, p. 1367-1385, DOI:10.1016/ S0020-7225(03)00037-5.

[18] Barlat, F., Lege, D.J., Brem, J.C. (1991). A sixcomponent yield function for anisotropic metals. International Journal of Plasticity, vol. 7, no. 7, p. 693712, DOI:10.1016/0749-6419(91)90052-Z.

[19] Lemu, H.G., Trzepieciński, T. (2013). Numerical and experimental study of friction behaviour in bending under tension test. Strojniski vestnik - Journal of Mechanical Engineering, vol. 59, no. 1, p. 41-49. DOI:10.5545/sv-jme.2012.383.

[20] Shih, H., Wilson, W., Saha, P. (1996). Modelling the influence of plastic strain on boundary friction in sheet metal forming. Proceedings of the NAMRC XXIV, p. 173-178.

[21] Sedlaček, M., Vilhena, L.M.S., Podgornik, B., Vižintin, J. (2011). Surface topography modelling for reduced friction. Strojniski vestnik - Journal of Mechanical Engineering, vol. 57, no. 9, p. 674-680, DOI:10.5545/ sv-jme.2010.140.

[22] Skarpelos, P., Morris, J.W. (1997). The effect of surface morphology on friction during forming of electrogalvanized sheet steel. Wear, vol. 212, no. 2, p. 165-172, DOI:10.1016/s0043-1648(97)00174-9.

[23] Li, X.Y., Tandon K.N. (2000). Microstructural characterization of mechanically mixed layer and wear debris in sliding wear of an Al alloy and an $\mathrm{Al}$ based composite. Wear, vol. 245, no. 1-2, p. 148-161. DOI:10.1016/S0043-1648(00)00475-0.

[24] Livatyali, H., Firat, M., Gurler, B., Ozsoy, M. (2010). An experimental analysis of drawing characteristics of a dual-phase steel through a round drawbead. Materials and Design, vol. 31, no. 3, p. 1639-1643. DOI:10.1016/j.matdes.2009.08.030. 